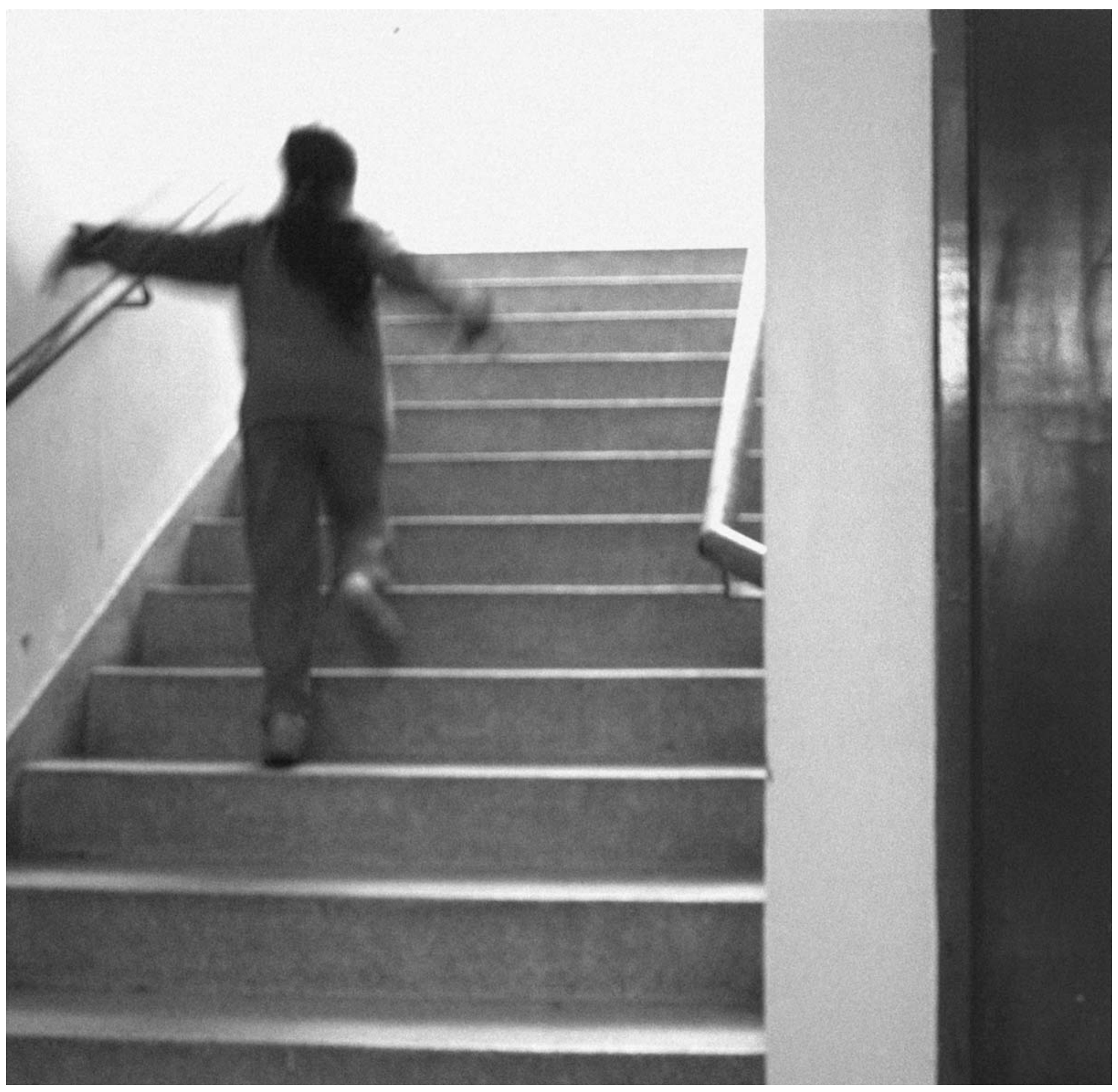




\section{A defesa de uma cultura avaliativa}

propósito deste relato é estimular o debate sobre a "cultura avaliativa". Para tanto, apresenta-se, em primeiro lugar, o conceito de avaliação, um dos pilares desta exposição e dos programas nacionais de avaliação do rendimento escolar. Em segundo lugar, elabora-se a idéia de "cultura avaliativa" no contexto educacional em geral e, em particular, com relação às avaliações massivas. Em terceiro lugar, expõem-se alguns fatores que favorecem ou inibem o desenvolvimento de uma cultura avaliativa, tendo como exemplo o caso do Chile. Por fim, examinamse os efeitos que a formação da cultura avaliativa pode ter sobre o sistema educacional, assim como sobre o debate político e público em geral.

\section{0 conceito de avaliação e os programas nacionais de avaliação do rendimento escolar}

O conceito de avaliação converteu-se em um dos elementos centrais do discurso educacional da atualidade. No entanto, como seu significado está longe de ser unanimemente aceito, será adotada aqui uma conceituação, para efeito desta exposição, que diz respeito ao seu entendimento como processo para a determinação do valor ou mérito de um objeto educacional submetido à avaliação, qualquer que seja ele.

Isso implica identificação, análise e aplicação de critérios ou padrões determinados para avaliar a qualidade, a utilidade, a efetividade ou o significado do objeto em questão.

O processo avaliativo emprega métodos de averiguação e juízo que incluem:

- a determinação de critérios ou padrões para julgar o valor ou mérito, especificando se eles serão absolutos ou relativos;

* ERika Himmel König é pesquisadora e professora catedrática da Pontifícia Universidade Católica do Chile. 
- a coleta de informação relevante;

- a aplicação dos critérios ou padrões para determinar o valor ou mérito, qualidade, utilidade, efetividade ou significado do objeto em questão.

Todo esse processo culmina com recomendações que orientam as ações necessárias para melhorar a qualidade, a utilidade, a efetividade ou o significado do objeto avaliativo, neste caso, sempre de caráter educacional. A avaliação é aplicada agora a aspectos muito variados, para averiguar, por exemplo, a aprendizagem dos alunos, a competência dos professores ou a qualidade das instituições escolares, dos planos e programas educacionais, dos programas de inovação pedagógica, das reformas educacionais e da própria educação.

$\mathrm{Na}$ presente década, os programas nacionais para avaliar a aprendizagem ou o rendimento dos alunos têm adquirido especial relevância. Esta tendência encontra suas raízes em diversos fatores que têm contribuído para a implantação desses programas. De um lado, durante várias décadas, os países centraram todos os seus esforços na expansão da cobertura dos sistemas de Educação, o que significou que a ênfase das políticas educacionais e dos investimentos no setor esteve focada nos instrumentos. Em outras palavras, construíram-se mais escolas e se contrataram mais professores para oferecer acesso à educação a toda a população em idade escolar.

No entanto, uma vez conquistado esse objetivo, surgiu a necessidade de se conhecer os resultados do esforço empregado. Sobretudo, porque se detectou, nos países em que o problema de cobertura foi sendo gradualmente solucionado, que a expansão dos sistemas educacionais foi realizada à custa da qualidade do serviço educativo, já que os investimentos requeridos superavam amplamente suas possibilidades econômicas.

Dessa forma, desponta um forte interesse político e público por indagar o que efetivamente os alunos aprendem na escola. Esta inquietação é reforçada pela Declaração Mundial sobre Educação para Todos (Unesco, 1990, art. 4 - Concentrar a atenção na aprendizagem), que assinala:

A tradução das oportunidades ampliadas de educação em desenvolvimento efetivo - para o indivíduo ou para a sociedade

- dependerá, em última instância, de, em razão dessas mesmas oportunidades, as pessoas aprenderem de fato, ou seja, apreenderem conhecimentos úteis, habilidades de raciocínio, aptidões e valores.
De outro lado, a economia exerce pressão cada vez maior sobre a educação, conseqüência do aumento do livre comércio e da concorrência entre as nações. Estas exigem mão-de-obra cada vez mais qualificada para atender ao lucro e à competitividade. Assim, recupera-se a confiança na educação como alicerce para o desenvolvimento do que se consagrou chamar de "capital humano", uma das dimensões cruciais no desenvolvimento das economias (Kellaghan, 1997; Tiana, 1999).

\section{Coexistência de sistemas}

A decisão de organismos internacionais (BID - Banco Interamericano de Desenvolvimento, OEA - Organização dos Estados Americanos, Banco Mundial, por exemplo) de oferecerem apoio financeiro ao setor educacional, tendo como contrapartida a demonstração de seu impacto sobre a melhoria dos vários sistemas educacionais, tem contribuído para impulsionar os programas de avaliação em andamento (Lockheed, 1992).

Nesse contexto, os sistemas nacionais de avaliação têm avançado, permitindo:

- adquirir informações acerca do êxito das metas educacionais;

- identificar variáveis internas e externas ao sistema que explicam as desigualdades nos resultados;

- prever com segurança o funcionamento do sistema no futuro;

- proporcionar indicadores sobre os itens mais pertinentes do sistema.

Os sistemas de avaliação compreendem, em geral, a aplicação de provas ou testes referentes ao êxito das aprendizagens esperadas nas áreas do conhecimento constituintes do currículo escolar, complementadas ocasionalmente com questionários sobre variáveis potencialmente explicativas da variabilidade dos resultados, que são disseminados entre os agentes educacionais diretos e indiretos.

Entre os propósitos assinalados mais freqüentemente para esses sistemas de avaliação, destacam-se:

- instituir e avaliar políticas educacionais;

- avaliar programas educacionais específicos;

- acompanhar as mudanças sobre os resultados educativos ao longo do tempo;

- responsabilizar professores, escolas, regiões e outras subdivisões administrativas pelas aprendizagens alcançadas pelos estudantes; 
- selecionar e distribuir os alunos por níveis educacionais superiores;

- atestar o êxito da aprendizagem dos estudantes;

- proporcionar dados aos pais e responsáveis sobre a qualidade da educação oferecida pelas escolas;

- diagnosticar necessidades de aprendizagem.

Como é muito difícil, senão impossível, atingir todos esses propósitos por meio apenas de um sistema de avaliação, freqüentemente coexistem dois ou mais sistemas com intenções diferentes (Lockheed, 1996; Greaney; Kellaghan, 1996). Em todo caso, espera-se que um sistema, ou programa, que se proponha a alcançar alguns dos propósitos enunciados:

- contribua para uma melhor compreensão do funcionamento do sistema educacional;

- proporcione as orientações necessárias para as tomadas de decisão de diversos atores em diferentes níveis;

- auxilie na melhoria da qualidade do serviço educativo.

Ou seja, supõe-se que a avaliação do rendimento escolar tenha um impacto sobre o próprio sistema educacional que vá muito além de proporcionar informação sobre si mesmo. Espera-se que as informações orientem decisões que conduzam a ações efetivas, que, por sua vez, possam ser avaliadas pelos próprios sistemas, sempre que difundidas clara e oportunamente, bem como que o programa, ou sistema, demonstre estabilidade ao longo do tempo.

\section{A "cultura avaliativa"}

\section{0 termo "cultura" encerra um conceito polissêmico e} complexo. Mais ainda se combinado com o de avaliação no âmbito educacional. Sem pretensão reducionista, mas no afã de chegar a um acordo para estimular a discussão, propõe-se entender por "cultura avaliativa" a combinação adicional de ações avaliativas formais que se difundem com a aplicação dos resultados de tais avaliações, para as tomadas de decisão e para o reconhecimento social da relevância da informação avaliativa. Em outros termos, propõe-se a seguinte equação:

\begin{tabular}{|cc} 
Cultura Avaliativa \\
\hline Difusão das \\
ações avaliativas
\end{tabular}$+\begin{gathered}\text { Aplicação dos } \\
\text { resultados }\end{gathered}+\begin{gathered}\text { Relevância social } \\
\text { da informação }\end{gathered}$

Já se mencionou que as ações avaliativas podem ser aplicadas com diferentes finalidades, mas, neste caso, o foco é a avaliação da aprendizagem dos alunos.

Dependendo de quais sejam os objetivos de um sistema de avaliação do rendimento escolar, eles podem ter impacto em diferentes áreas ou setores, porém, alguns deles têm efeito sobre o próprio sistema de avaliação. 0 diagrama 1 sintetiza isso:

\section{DIAGRAMA 1}

ÁREAS DE INFLUÊNCIA DOS PROGRAMAS NACIONAIS DE AVALIAÇÃO DO RENDIMENTO ESCOLAR

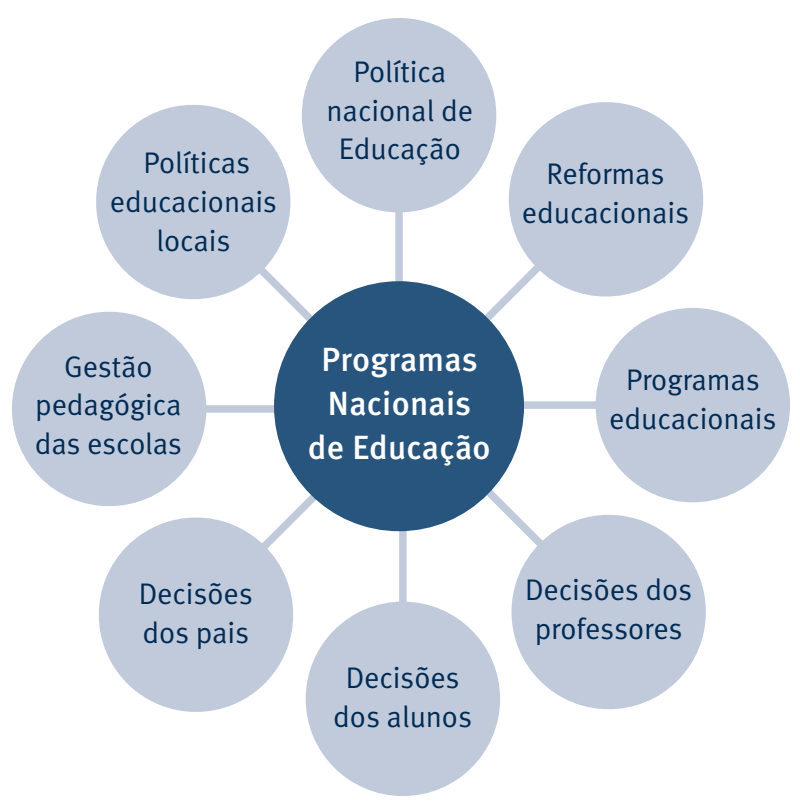

Desse modo, se um programa de avaliação do rendimento escolar tem o objetivo de gerar informações para instituir e avaliar políticas educacionais e monitorar os resultados educativos, os resultados da avaliação podem influir na proposta de novas políticas educativas, que incluam, por exemplo, reformas educacionais. É possível, ainda, que tenha efeitos sobre a gestão pedagógica das escolas, assim como em relação às decisões adotadas pelos professores referentes à condução do processo educativo.

Por outro lado, a implementação de uma reforma educacional pode gerar uma necessidade avaliativa específica que influa nas características de um programa nacional de avaliação. Em outras palavras, as diferentes áreas que sofrem a influência de um programa de avaliação podem, por sua vez, incidir sobre ele, gerando novas necessidades avaliativas. 
Cabe assinalar, contudo, que esses efeitos estão diretamente relacionados à utilização efetiva dos resultados das avaliações para as tomadas de decisão, o que nem sempre ocorre. Na literatura especializada, diversos autores (Alkin; Daillak; White, 1979; Alkin, 1985; Brown; Newman; Rivers, 1985) reconhecem duas formas de conceituar o uso das informações, quais sejam:

- a denominada "perspectiva da corrente principal (mainstream perspective)" e

- a "concepção alternativa".

A primeira concebe esse uso como o impacto direto e rápido da informação avaliativa sobre o sistema ou programa educacional - em geral, o objeto da avaliação. Dessa forma, o uso é caracterizado como um evento e não como um processo, susceptível de ser iniciado desde o momento em que se planeja um sistema de avaliação.

A dimensão desse uso é, assim, desmembrada em duas categorias principais: uso versus não-uso. Aderir a esta corrente implica presumir que se aceita a utilização da avaliação somente quando ela produz efeitos, como: introdução de reformas educacionais imediatas, troca de um programa por outro ou modificações drásticas nas estratégias pedagógicas. Essas ações radicais não ocorrem necessariamente, já que há um conjunto de fatores que condiciona o emprego da informação avaliativa e depende das características do processo de avaliação e dos resultados proporcionados. Deve-se considerar ainda que as tomadas de decisão são influenciadas por outros fatores, além dos resultados de avaliações.

King e Pechman (1984), numa tentativa de aclarar essa concepção de uso, indicam que, em sua base, encontramse alguns pressupostos questionáveis, como:

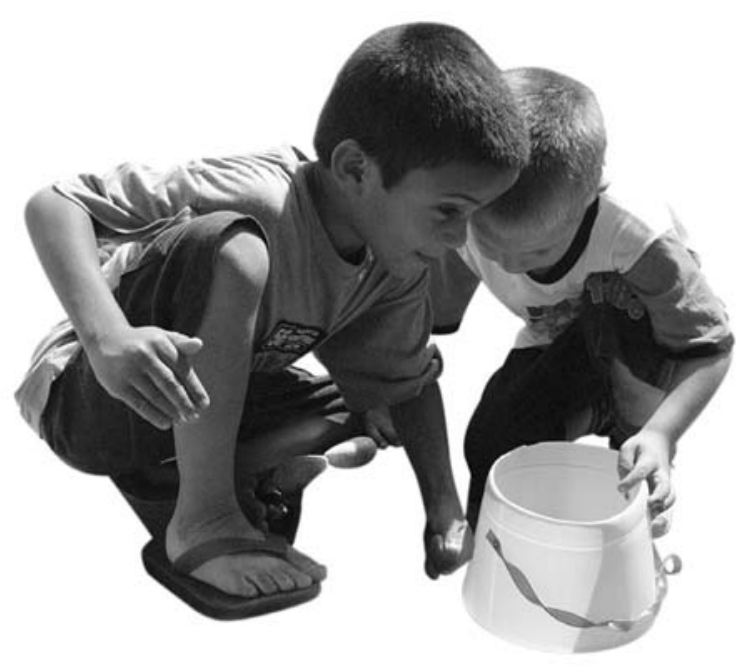

- considerar que as decisões podem ser adotadas de um modo classicamente racional, sem considerar as variáveis políticas, sociais e organizacionais que nelas influem;

- entender que a informação avaliativa constitui o único fator desencadeante de efeitos imediatos e observáveis (o mito do Big Bang);

- supor que a qualidade dos informes avaliativos é condição suficiente para seu uso cabal;

- julgar que a colaboração ativa entre os avaliadores e os responsáveis pelas decisões incrementará necessariamente o uso.

\section{0 impacto da avaliação não é imediato}

A esse respeito, pode-se mencionar que os gestores do Programa de Avaliação do Rendimento que se desenvolveu no Chile, entre 1982 e 1984, começaram a operação do programa justamente com a adoção da maioria desses pressupostos, já que supuseram, erroneamente, que, a partir de tal informação, professores, diretores e autoridades educacionais conceberiam propostas de ação de vulto, mediante um processo de autogestão e autocontrole. No entanto, logo se deram conta da fragilidade dos pressupostos mencionados e aderiram à concepção alternativa.

Outro exemplo que ilustra esse posicionamento encontra-se em Schiefelbein (1992, p. 264), que julga o impacto do Programa de Avaliação do Rendimento apenas pela constatação de que os resultados alcançados pelos alunos não apresentaram variações significativas em um período, assinalando o seguinte: “...esses antecedentes demonstram que as expectativas acerca da melhoria dos rendimentos acadêmicos são demasiado elevadas".

Por sua vez, o enfoque alternativo do uso da informação avaliativa é concebido como um processo gradual, no qual essa informação, acompanhada de outros antecedentes, pode gerar pequenas ações que modificam paulatinamente a situação inicial detectada. Dessa perspectiva, o impacto da avaliação não é imediato, podendo demorar anos e ocorrer em combinação com outras informações contextuais, ou sob diferentes circunstâncias, o que resulta na possibilidade de adoção de significados diversos em distintos tempos (Braskamp, 1982). 
King e Pechman (1984) explicam que é possivel reconhecer ao menos três níveis de uso da informação avaliativa:

- simbólico ou persuasivo;

- conceitual;

- instrumental.

A eles, pode-se agregar uma quarta categoria de "não-uso instrumental". A relação entre produção de dados avaliativos, informações contextuais e seu emprego como instrumento para as tomadas de decisão é sintetizada no Quadro 1.

Quando o emprego dos resultados das avaliações se situa no nível simbólico ou persuasivo, é utilizado com fins pessoais. Por exemplo, os resultados de uma avaliação podem ser usados por um diretor de escola para justificar seu bom desempenho, dando-lhe um pretexto que irá colaborar para sua permanência no cargo. Esta modalidade exige, assim, uma análise do contexto em que opera, para avaliar adequadamente as intenções positivas ou negativas subjacentes. Nesse caso, a avaliação é empregada mais como justificativa para certas decisões do que como instrumento para embasá-las e, às vezes, costuma ser usada nesse sentido por razões político-administrativas.
Pode-se ainda incluir, nesse primeiro nível, um efeito dos sistemas de avaliação do rendimento amplamente discutido na literatura (Greaney; Kellaghan, 1996), que é sua influência no ensino. Na verdade, nenhuma aplicação externa de provas é neutra. E os professores, quando percebem, de algum modo, a importância dos resultados dos testes, começam a orientar o processo de ensino principalmente para os conteúdos e objetivos requeridos nas provas, acabando por justificar sua forma de abordar o currículo escolar a partir do que as provas contemplam.

Entretanto, o uso conceitual implica que a avaliação deve provocar, no usuário, uma reflexão mais detida acerca do objeto da avaliação, de forma que ele possa reconhecer que existem acertos e dificuldades para sua implementação, levando-o, assim, a uma mudança de postura, processo que pode, em longo prazo, estimulá-lo a tomar algumas decisões mais específicas.

Por exemplo, o diretor de uma escola pode atribuir o baixo desempenho em uma avaliação do rendimento à falta de empatia dos alunos com os professores. Diante dessa conclusão, ele convoca os professores para uma jornada de discussões, na tentativa de buscar as causas do problema. Este exemplo mostra que, mesmo sem empre-

\section{QUADRO 1}

SISTEMA NACIONAL DE AVALIAÇÃO DO RENDIMENTO ESCOLAR

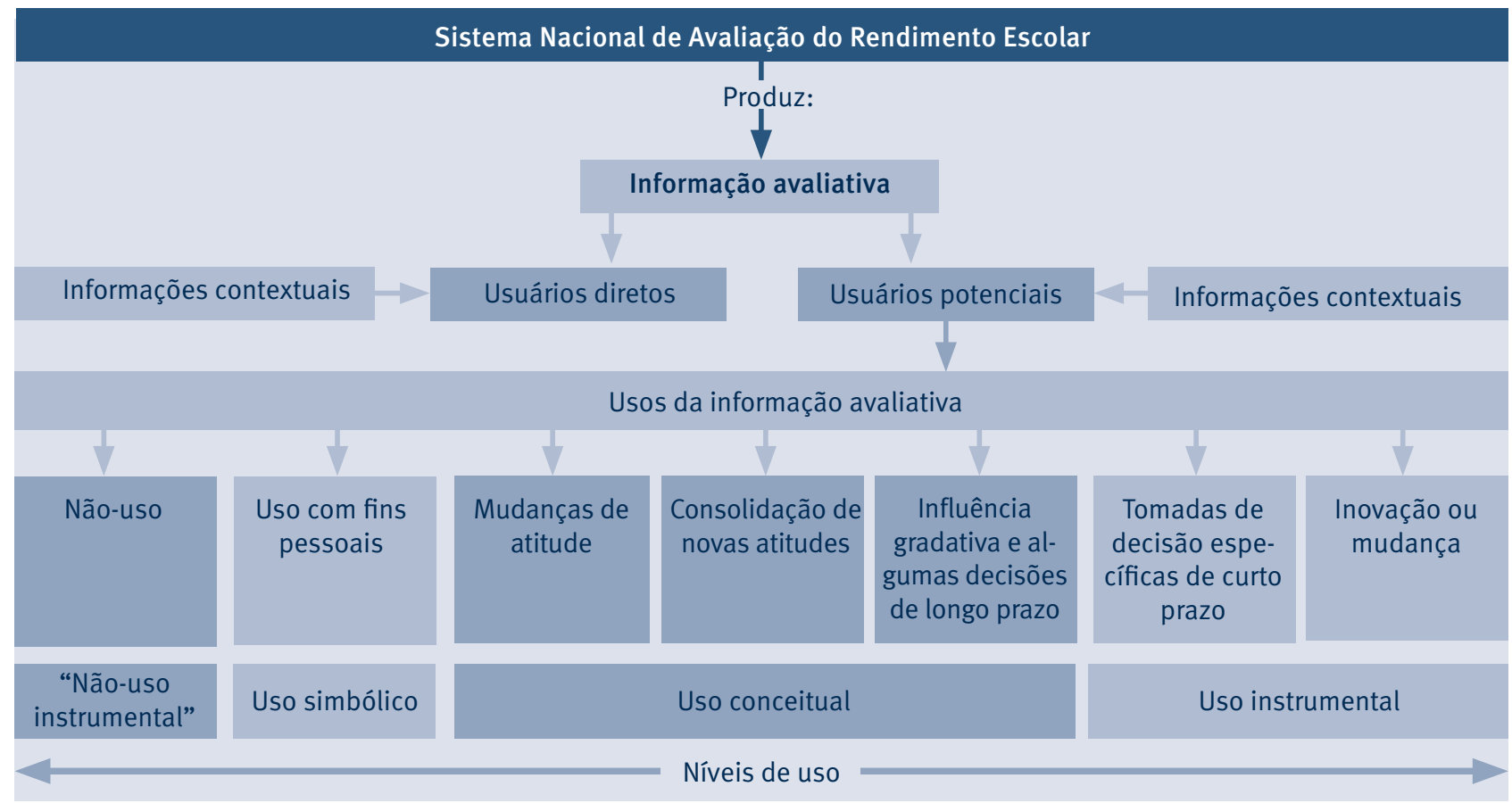


ender ações específicas, a informação instigou o usuário a uma reflexão sobre o tema, a qual, eventualmente, poderá traduzir-se em pequenas ações, como promover encontros informais entre professores e alunos.

Por sua vez, a concepção do uso como instrumental acontece quando se pode reconhecer claramente que as informações geradas pela avaliação constituem a base e estão diretamente vinculadas às decisões tomadas por seu usuário.

Empregando o mesmo exemplo anterior, se o diretor decidir consultar sistematicamente as opiniões dos alunos sobre os aspectos que consideram positivos e negativos na escola, para implantar um programa destinado a melhorar a relação dos alunos com os professores, estará utilizando instrumentalmente a informação proporcionada pelo sistema de avaliação.

Por fim, quando a informação é conscientemente descartada pelos usuários, ela pode ser denominada de “nãouso instrumental". Digamos, por exemplo, que o informe dos resultados de uma avaliação de rendimento mostre que os alunos de um município obtiveram um desempenho extremamente baixo em ortografia, na $4^{\underline{a}}$ série, e o departamento técnico-pedagógico considere que ortografia não é um objetivo educativo fundamental para essa série. Então, ainda que tome ciência do fato, provavelmente o departamento não empreenderá qualquer ação para melhorar o êxito dos alunos nessa disciplina.

Ao analisar o uso da informação de acordo com esse modelo, é possível reconhecer os efeitos de um sistema nacional de avaliação da aprendizagem, que pode desdobrar-se em múltiplas ações, não necessariamente com rápida melhoria dos rendimentos. Ainda assim, tais intervenções podem levar, em médio ou longo prazo, a uma melhora da aprendizagem dos alunos.

Instaurar uma cultura avaliativa implica levar a cabo avaliações educativas formais e periódicas, assim como gerar e difundir uma estratégia de divulgação de seus possíveis usos, seja em relação à aprendizagem, seja no que diz respeito à competência profissional dos professores. Esta também é uma forma de demonstrar a relevância social da informação avaliativa.

\section{Fatores que facilitam ou inibem o desenvolvimento de uma cultura avaliativa}

\section{É possível reconhecer quatro fatores principais:}

- a tradição avaliativa do país;
- as políticas educacionais;

- a legislação ou as normas;

- as estratégias e formas de divulgação de resultados.

Eles podem atuar nos dois sentidos, contribuindo ou dificultando o desenvolvimento da cultura avaliativa.

DIAGRAMA 2

FATORES QUE FACILITAM OU INIBEM O DESENVOLVIMENTO DE UMA CULTURA AVALIATIVA

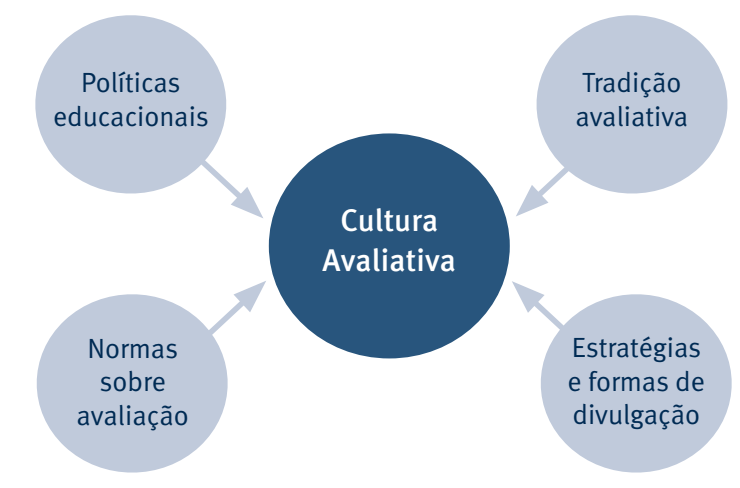

\section{A tradição avaliativa do país}

Este fator relaciona-se basicamente à frequiência com que se realizam ações avaliativas em um país, e também aos recursos humanos qualificados disponiveis para concretizá-las. Com efeito, passar muitos anos tentando realizar ações avaliativas que envolvam massivamente alunos, pais e professores aumenta a probabilidade de gerar uma cultura avaliativa. Isso não quer dizer necessariamente que ela será bem-sucedida, tampouco que o esforço empreendido terá apoio permanente.

No entanto, é requisito básico que essas ações avaliativas sejam implementadas, em todas as ocasiões, por profissionais competentes e com credibilidade para a opinião pública. Em apresentações sobre os sistemas de avaliação desenvolvidos no Chile, foram mencionadas fundamentalmente três experiências cuja base era esse fator facilitador:

- o Sistema de Ingresso à Educação Superior, vigente no país desde 1967;

- o Programa de Avaliação do Rendimento Escolar (PER - Programa de Evaluación del Rendimiento Escolar), realizado entre 1982 e 1984;

- o Sistema Nacional de Medição da Qualidade da Educação (SIMCE - Sistema Nacional de Medición de Calidad de la Educación), que vigora desde 1989 (Himmel, 1997). 
A essas iniciativas, podem ser agregadas, no caso do Chile, outras, ocorridas em um período mais extenso. A esse respeito, pode-se assinalar que as primeiras tentativas ocorreram em princípios da década de 1930. Foram realizadas por um conjunto de educadores, os quais fizeram pós-graduação na Europa e nos Estados Unidos. Elas consistiram na adaptação e na elaboração de numerosas provas escolares (Aritmética, Ortografia, vocabulário, leitura silenciosa e compreensão de texto, História, Geografia e outras disciplinas), ministradas a aproximadamente 10 mil alunos.

Também se pode mencionar a Prova Nacional, aplicada, entre 1966 e 1968, por uma equipe de especialistas do Ministério da Educação do Chile. Na Colômbia, México e Costa Rica, há 30 ou 40 anos, especialistas também realizam um trabalho nessa área, que se tem desenvolvido mais nos últimos dez anos.

Como se pode verificar, a tradição leva à formação de uma cultura avaliativa, desde que a atividade seja mantida ao longo do tempo.

\section{Políticas educacionais}

Outro fator que contribui para a geração de uma cultura avaliativa são as políticas educacionais que promovem ações nesse sentido. Pode-se afirmar que, quando contemplada em uma política educacional, a avaliação certamente passa a ser aplicada e, eventualmente, utilizada para as tomadas de decisão.

Alguns exemplos confirmam isso, como a Reforma Educacional realizada no Chile, em 1965, que implicou uma mudança no ensino básico, nos planos e programas, no enfoque do processo educativo e na continuidade dos estudos no ensino médio (a Prova Nacional tinha como propósito encaminhar os estudantes para o ensino médio ou profissionalizante).

Por sua vez, a descentralização administrativa do sistema educacional é a origem do Programa de Avaliação do Rendimento Escolar e do Sistema Nacional de Medição da Qualidade da Educação. No entanto, convém assinalar também que, no caso do primeiro, a política educacional foi formulada e implementada de forma incompleta.

Na verdade, o Programa de Avaliação do Rendimento Escolar foi concebido, sobretudo, como um sistema de avaliação massiva que desencadearia ações de melhoria desde a base, que são as escolas, sem, contudo, an- gariar apoio técnico e econômico do Ministério da Educação, que autorizara a execução das ações. Esta carência foi remediada no caso do Sistema Nacional de Medição, já que ele foi acompanhado de numerosos programas de apoio às escolas cujos alunos demonstrassem os rendimentos mais baixos (Himmel, 1997).

\section{A legislação ou as normas}

Este é o fator que legitima a avaliação. Tanto no caso da Prova Nacional, quanto no do Programa de Avaliação do Rendimento Escolar, não houve uma legislação ou norma definida que regulasse sua obrigatoriedade, características, periodicidade etc. Já em relação ao Sistema Nacional de Medição da Qualidade da Educação e ao Sistema de Ingresso à Educação Superior, existem disposições a respeito. 0 primeiro encontra-se oficialmente reconhecido em uma das leis orgânicas sobre educação, e o segundo, pela normativa do ConseIho de Reitores das universidades que recebem subsídios estatais.

Além disso, uma parte desse sistema de avaliação a Prova de Aptidão Acadêmica - encontra-se vinculada ao financiamento universitário pela legislação vigente. Nestes últimos exemplos, vê-se que a legislação e/ou a normativa contribuíram para a continuidade e a legitimidade dos sistemas de avaliação que, por sua vez, facilitaram o desenvolvimento da cultura avaliativa.

\section{As estratégias e formas de divulgação de resultados}

Este último fator tem efeito decisivo para a formação da cultura avaliativa. Como mencionado anteriormente, ela tem dois componentes: as ações de avaliação e o uso da informação. Ainda que eles atuem principalmente na realização das ações de avaliação, as estratégias e formas de divulgação de resultados incidem mais especificamente sobre o uso da informação produzida. Na verdade, se a informação gerada pelos processos avaliativos não for divulgada ou acabar sendo disseminada por meio de uma estratégia equivocada, dificilmente poderá ser utilizada nas tomadas de decisão.

A divulgação compreende ao menos quatro fases:

- antes do processo avaliativo;

- durante o processo;

- para demonstrar os resultados;

- de continuidade. 


\section{Antes do processo}

\section{A difusão prévia tem o propósito de informar acerca} dos objetivos, características e etapas do processo. Trata-se de uma fase de sensibilização dos que serão afetados e envolvidos pela avaliação. Pode-se pensar que, uma vez que um programa ou sistema de avaliação se encontre instaurado, esta etapa não seja necessária. No entanto, esses sistemas não são estáticos. São dinâmicos e passíveis de mudanças ao longo do tempo, no que se refere, por exemplo, a conteúdos, modalidades, prazos, público-alvo, abrangência etc., de modo que sempre é necessário sensibilizar os envolvidos.

Assim, no Sistema Nacional de Medição da Qualidade da Educação, a informação anterior ao processo costuma consistir nas seguintes ações:

- Distribuição de um folheto aos estabelecimentos de ensino, quatro meses antes da aplicação das provas, com descrição dos objetivos, relação de datas e comunicado de que, posteriormente, haverá explicações mais técnicas.

- Envio de um informativo aos pais dos alunos, descrevendo os objetivos do Sistema, as datas das provas e anunciando a importância de sua participação, com o objetivo de despertar neles o interesse pelo programa e de obter sua cooperação, em parceria com os colégios, na formação dos filhos.

- Produção de um vídeo de cerca de 15 minutos, com caráter eminentemente motivacional, divulgado primeiro aos supervisores, que, posteriormente, multiplicarão a informação, repassando-a a diretores e professores. Seus objetivos principais:

- contribuir com o desenvolvimento de uma atitude positiva em relação ao programa nos diferentes niveis do sistema educacional;

- promover seus fundamentos e propósitos de maneira compreensível para todos;

- apoiar as atividades de divulgação realizadas pelas equipes de supervisores em nível local.

- Distribuição de cartazes alusivos ao programa em todas as escolas e lugares públicos, algumas vezes acompanhados de um calendário do ano.

- Difusão nacional de um programa de TV, com ampla cobertura jornalística do processo.

- Disseminação dos aspectos técnicos do programa a professores e diretores, por meio de um folheto, detalhando os fundamentos do Sistema, a forma de elaboração dos instrumentos de medição empregados e suas características técnicas, e exemplos dos objetivos e das questões das provas. Além disso, o preparo de um conjunto de transparências para divulgação local pode auxiliar nas palestras realizadas pelos supervisores.

\section{Durante o processo}

\section{A finalidade de transmitir a informação durante 0} processo de avaliação objetiva é chamar a atenção de toda a opinião pública para o processo em andamento. No Sistema Nacional de Medição da Qualidade da Educação, a fim de que os meios de comunicação se encarreguem da difusão, normalmente se elaboram comunicados para a imprensa, divulgados no dia anterior ao início da aplicação das provas. Além disso, as autoridades superiores do Ministério da Educação, incluindo o ministro, visitam e se mostram presentes nos locais de aplicação no dia em que começa o processo.

\section{Comunicação dos resultados}

\section{No que diz respeito à disseminação de resultados,} é necessário advertir que ela deve condizer com cada público específico e, sobretudo, ser feita em momento oportuno. É necessário distinguir, ao menos, a informação voltada às autoridades daquela dirigida aos professores, aos pais, aos especialistas em avaliação e à opinião pública. 0 tipo de informação fornecido a cada público depende do grau de desenvolvimento da cultura avaliativa.

Dessa maneira, se tal cultura se encontrar em uma etapa muito incipiente, será necessário proporcionar uma informação mais simples, mas nunca simplista. Ao contrário, à medida que a cultura avaliativa se mostrar mais desenvolvida, poder-se-á difundir uma informação cada vez mais sofisticada, sempre se levando em conta o nível de conhecimento dos diferentes públicos. Como o tipo de informação que se divulga também muda ao longo do tempo, é necessário incorporar manuais de interpretação ao programa de disseminação de resultados e, ainda, no caso dos sistemas de avaliação da aprendizagem, manuais com orientações pedagógicas. 


\section{Continuidade}

\section{A continuidade do programa também requer um proces-} so de divulgação. Basicamente, trata-se de disseminar as ações empreendidas pelos diferentes agentes para superar rendimentos insuficientes e monitorar o uso dos resultados. No Chile, por exemplo, foi elaborado um índice de vulnerabilidade educacional baseado nos resultados do Sistema Nacional de Medição da Qualidade da Educação, o qual tem servido para destinar recursos e apoio às escolas com resultados mais deficitários de seus alunos. Uma das iniciativas consistiu em projetos de melhoria educacional, formulados pelas escolas a partir de um diagnóstico de suas necessidades educativas. Os resultados da execução desses projetos são divulgados em publicações e exposições.

É ainda importante assinalar que nenhum desses quatro fatores é suficiente, por si, para gerar uma cultura avaliativa. Não basta, portanto, que um país disponha de uma tradição em avaliação, de uma legislação que a promova ou ainda de políticas educacionais que a incentivem. São necessários todos esses fatores e, mais especificamente, a forma ou a estratégia de divulgação, que é o que permite fazer os diferentes atores assimilarem a cultura avaliativa.

\section{Efeitos da cultura avaliativa sobre o sistema educacional e sobre o debate político e público em geral}

\section{A cultura avaliativa pode produzir um efeito virtuoso ou} um círculo vicioso sobre o sistema educacional e sobre o debate político e público. 0 efeito virtuoso acontece quando há melhoria no serviço educativo, de acordo com o consenso sobre o significado de "melhoria", traduzido freqüentemente em priorizar a área da Educação e em the destinar mais recursos.

Outro efeito positivo que deriva da cultura avaliativa é que os critérios ou padrões para julgar o desempenho dos alunos são mais bem definidos e com expectativas mais elevadas, o que contribui para que os educandos adquiram conhecimentos úteis e atualizados, maior habilidade de pensamento, destrezas mais complexas e valores, em conformidade com a declaração da Unesco de 1990. Dessa forma, conquistam-se recursos humanos melhores, ou seja, desenvolve-se um "capital humano" cada vez mais valioso.

Por sua vez, o círculo vicioso se produz quando os resultados da avaliação se traduzem meramente em um trabalho para lograr alcançar o que o sistema de avaliação pretende explicitamente. É claro que nenhum sistema de avaliação pode abarcar todos os propósitos e diferentes aspectos do processo educativo, portanto, sempre proporcionará uma visão parcial.

Em outros termos, os alunos aprendem o que o sistema de avaliação pretende; os diretores contratam os professores que obtêm os melhores resultados de seus alunos; e os pais, quando podem, escolhem as escolas para os filhos de acordo com este mesmo critério.

Este último efeito leva à conquista não das metas educacionais nacionais, e sim das contempladas no sistema de avaliação, pois tudo o que não é considerado no sistema ou programa é relegado a segundo plano ou simplesmente suprimido, já que é menos importante, tornando, assim, a educação desvirtuada e empobrecida.

Com esta síntese, espera-se haver alcançado o objetivo de estimular o debate acerca da cultura avaliativa, dos fatores que a promovem e dos efeitos que pode ter.

\section{Referências}

ALKIN, M. The feasibility of measuring educational attainment in chilean schools. Consultant Report, Santiago, n. 8, 1981.

ALKIN, M. C. A guide for evaluation decision makers. Beverly Hills: Sage Publications, 1985.

ALKIN, M. C.; DAILLAK, R.; WHITE, P. Using evaluations: does evaluation make a difference? Beverly Hills: Sage Publications, 1979.

BRASKAMP, A. L. A definition of use. Studies in Educational Evaluation, v. 8, n. 2, p. $169-74,1982$.

BROWN, R. D.; NEWMAN, D.; RIVERS, L. An exploratory study of contextual factors as influences on schoolboard evaluation information needs for decisionmaking. Educational Evaluation and Policy Analysis, v. 7, n. 4, p. 437-45, 1985.

GREANEY, V.; KELLAGHAN, T. Monitoring the learning outcomes of education systems: directions in development. Washington, DC: World Bank, 1996.

HIMMEL, E. Impacto social de los sistemas de evaluación del rendimiento escolar. In: ALVAREZ, B.; RUIZ-CASARES, M. (Ed.). Evaluación y reforma educativa: opciones de política. Santiago de Chile: Preal, 1997.

KELLAGHAN, T. Seguimiento de los resultados educativos nacionales. In: ALVAREZ, B.; RUIZ-CASARES, M. (Ed.). Evaluación y reforma educativa: opciones de política. Santiago de Chile: Preal, 1997.

KING, J. A.; PECHMAN, E. M. Pinning a wave to the shore: conceptualizing evaluation use in school systems. Educational Evaluation and Policy Analysis, v. 6, n. 3, p. 241-51, 1984 .

LOCKHEED, M. E. World Bank support for capacity building: the challenge of educational assessment. Washington, DC: World Bank, 1992.

LOCKHEED, M. International context for assessments. In: MURPHY, P.; GREANY, V.; LOCKHEED, M.; ROJAS, C. (Ed.). National assessments: testing the system. Washington, DC: World Bank, 1996.

SCHIEFELBEIN, E. Análisis del SIMCE y sugerencias para mejorar su impacto en la calidad. In: GÓMEZ, S. (Ed.). La realidad en cifras: estadísticas sociales. Santiago de Chile: FLACSO/INE/UNRISD, 1992.

TIANA, A. La evaluación y la calidad dos cuestiones sometidas a discusión. Ensaio: Avaliação e Políticas Públicas em Educação, v. 7, n. 22, p. 26-46, 1999.

UNESCO. World Declaration on Education for All. Meeting Basic Learning Needs. In: WORLD CONFERENCE ON EDUCATION FOR ALL, 1990, Jomtien, Thailand. 